\title{
Diego de Guadalajara y la física newtoniana en la CONSTRUCCIÓN DE RELOJES NOVOHISPANOS DEL SIGLO XVIII
}

\author{
Juan Manuel Espinosa Sánchez*

\begin{abstract}
"Para unos el tiempo se vincula a las manecillas del reloj de la iglesia; para otros ese binomio tiempo-técnica se enlaza al conocimiento de la naturaleza; y no faltan los que van más allá, los que se dedican al esfuerzo para ahorrar el esfuerzo y, desde luego, los que piensan en el lucro y en la voluntad del poder económico".
\end{abstract} \\ Arturo Azuela \\ Las Ciencias y el Quijote
}

\section{Resumen}

Este trabajo está enfocado al estudio de la física newtoniana en la Nueva España del siglo xVIII. Explicaremos el periódico de Diego de Guadalajara llamado Advertencias y Reflexiones varias conducentes al buen uso de los Reloxes grandes y pequeños y su regulación; asimismo sus Instrumentos con método, para su mejor conservación, editado en la ciudad de México en la imprenta de Felipe de Zúñiga y Ontiveros en 1777, que trata sobre la aplicación de las leyes de la mecánica newtoniana en la fabricación de relojes mecánicos. De manera paralela se escribió una semblanza biográfica del personaje para mostrar sus conocimientos en la reparación y construcción de instrumentos científicos, relacionados con la astronomía observacional.

\footnotetext{
* Profesor-investigador de la Universidad de Quintana Roo y estancia de investigación en el Instituto de Investigaciones Históricas de la Universidad Michoacana de San Nicolás de Hidalgo 2013-2014.
}

1 Azuela, Las Ciencias y el Quijote, p. 88. 
Palabras clave: Diego de Guadalajara, relojes mecánicos, mecánica newtoniana, Academia de San Carlos, matemáticas y cálculo.

\begin{abstract}
The present paper focuses on the study of Newtonian physics in the New Spain of the 18th century. We will explain Diego de Guadalajara's paper entitled Advertencias y Reflexiones varias conducentes al buen uso de los Reloxes grandes y pequeños y su regulación: 'Various warnings and reflections towards the good use of big and small watches and their regulation; as well as some other Instruments, to help their conservation in the best possible way, published in 1777 in Felipe de Zúñiga y Ontiveros's printing house in Mexico City. A biography of Guadalajara was also written, due to the great importance of his knowledge in the reparation and manufacturing of scientific instruments related to observational astronomy.
\end{abstract}

Keywords: Diego de Guadalajara, mechanical watches, Newtonian mechanics, San Carlos Academy, Mathematics and calculus.

\title{
Introducción
}

En el último tercio del siglo XVIII en la Nueva España floreció un grupo de relojeros, quienes reparaban y construían relojes de sol y mecánicos, a ellos perteneció Diego de Guadalajara y Tello, quien además fue profesor de matemáticas de la Academia de San Carlos, asimismo, escribió un periódico de relojería en 1777 con el título Advertencias y Reflexiones conducentes al buen uso de los Reloxes y otros Instrumentos Matemáticos, Físicos y Mecánicos, en donde para la elaboración de la maquinaría del reloj se usó la mecánica de Isaac Newton, que está inserta en la obra los Principios Matemáticos de la Filosofía Natural, por lo cual, el sabio De Guadalajara se convirtió en seguidor de la física newtoniana en suelo novohispano. 


\section{Datos bibliográficos de Diego de Guadalajara y Tello}

De Diego de Guadalajara y Tello no existe una biografía; varios pasajes de su vida permanecen oscuros, la fecha de su nacimiento está datada en $1742,{ }^{2}$ en la ciudad de México, como se asienta en un documento localizado en el Archivo General de la Nación en el fondo Desagüe, fechado entre 1802$1804,{ }^{3}$ relativo a las labores de la obra de Huehuetoca.

Aún se desconocen los colegios donde estudió De Guadalajara, pero se sabe de su participación científica con sus contemporáneos. Con Antonio de León y Gama realizó observaciones astronómicas en su observatorio personal, por sus dotes en la reparación de instrumentos científicos colaboró en la expedición de Malaspina, al componer varios aparatos, para tal fin redactó Memoria de los reparos y composiciones que se han hecho en los instrumentos matemáticos pertenecientes al rey de orden del señor Dionisio Galiano capitán de fragata, en 1791. Dicha memoria está perdida, ${ }^{4}$ pero tenemos constancia de los instrumentos que reparó: un círculo de Adams, un péndulo de Hellicot, un acromático de bronce y un reloj de Arnold. ${ }^{5}$ Además, él y Joaquín Velázquez de León construyeron conjuntamente telescopios para sus observaciones astronómicas. ${ }^{6}$

Diego de Guadalajara fue constructor y reparador de instrumentos científicos de la referida comisión científica de Malespina; las fuentes consultadas en el presente trabajo no indican que fuera experto en el armado de relojes mecánicos, tampoco se menciona que tuviera un "taller de relojería”, pero reparó telescopios, brújulas, cuadrantes y construyó relojes solares, uno de ellos se localiza en la Universidad de Oxford y pertenece a la colección del Museo de Historia de la Ciencia, el otro está ubicado en el Museo Franz Mayer de la ciudad de México, “ambos relojes son del tipo Ausburg, con un círculo de las hojas cortado o en forma de media luna, el segundo posee un inclómetro graduado para ser latitudes de las ciudades novohispanas (...) ubicadas entre los $40^{\circ}$ y $50^{\circ}$ del hemisferio norte".

2 Archivo General de la Nación (en adelante AGN), Matrimonios, vol. 112, exp. 24, f. 200v.

3 AGN, Desagüe, vol. 31, exp. 1, ff.1r-4r.

4 González Claverán, La Expedición Científica de Malaspina en la Nueva España (1789-1794), p. 332.

5 AGN, Historia, vol. 397, f. 413r.

6 Espinosa Sánchez, "La óptica novohispana en la segunda mitad del siglo XVIII", pp. 66-67.

7 Cházaro "Los instrumentos científicos de la Nueva España: circulación, usos y transformaciones de la medición”, pp. 745-746. 
También contribuyó en la formación del laboratorio del Real Seminario de Minería vendiendo instrumentos científicos y brújulas, desconocemos con qué tipo de instrumentales dotó al colegio de Minería, aunque sabemos que en 1803 contó con los siguientes aparatos: Ramsden, Adams, Le Noir y Luis Berthaud. ${ }^{8}$

Por otra parte, fue relojero y como tal editó el periódico Advertencias y Reflexiones más conducentes al buen usó de los relojes, del cual la Royal Society de Londres mencionó que se trataba del primer periódico especializado en relojes del mundo. En dicha obra mencionó a los relojeros ingleses y de Europa continental, como Huygens, Hautefeville, Hook, Berthoud, Sully, Harrison, Le Roy, Huberte, Elicot, Evans, San Levy, Cabrier, entre otros.

En su diario, De Guadalajara menciona que la geometría es importante por la exactitud de las medidas, la mecánica para explicar correctamente la potencia motriz, la analítica, la cual sirve en la resolución de los diversos problemas en la relojería, el dibujo en función de dar proporción y simetría y por último la música para brindar un sonido de campanas y flautas.

Tuvo conocimiento de los adelantos técnicos de los ingleses en la construcción de relojes mecánicos. Aquéllos aplicaban los teoremas de la mecánica newtoniana en la utilización de la energía motriz del reloj; un sistema oscilatorio, que permitía las transformaciones de energía cinética a energía potencial. Los primeros en usarlo fueron Fromanteel, Tompion y Quare, cuyos relojes tienen manecillas, marcan la hora, los minutos y en ocasiones los segundos. ${ }^{10}$ En la técnica relojera, los ingleses fueron innovadores al incrustar rubíes y usar el temple de acero en los relojes marítimos. De Guadalajara señala que la invención inglesa se debió a las matemáticas y experimentos físicos para explicar el movimiento. ${ }^{11}$ En su diario mencionó a John Harrison como un genio de la relojería inglesa.

8 Ramos Lara, Difusión e institucionalización de la mecánica newtoniana en México en el siglo XVIII, p. 70. 9 De Guadalajara y Tello, Advertencias y Reflexiones conducentes al buen usó de los Reloxes y otros Instrumentos Matemáticos, Físicos y Mecánicos, p. 2.

10 Attali, Historias del Tiempo, p.138. Véase De Guadalajara, op. cit., pp. 4-5.

11 De Guadalajara, op. cit., núm.5, septiembre 12 de 1777, pp.1- 2. 
En la parroquia del pueblo de Barrow en Lincolnshire le prestaron libros y estudió varias obras científicas, como la Filosofía de la Naturaleza de Nicholas Saunderson; en 1712 leyó los Principia de Isaac Newton y "reforzó sus conceptos del mundo natural". ${ }^{12}$ Los Principia del sabio inglés han tenido alcances científicos y técnicos con una revolución de ambas ramas gracias al desarrollo de la matemática, con el cálculo infinitesimal, y a que así se preparó el camino para la filosofía natural de la Ilustración, regida por la ciencia newtoniana con un razonamiento matemático para explicar la naturaleza y el modo de construir instrumentos científicos. ${ }^{13}$

De gran trascendencia fue la postura newtoniana en el desarrollo de la técnica, debido a que en el siglo Xvi los relojes mecánicos fueron imprecisos y no funcionaron con los cambios de temperatura como sucedía en altamar. En el siglo XVII Huygens construyó el reloj de péndulo, el cual tuvo buenos resultados en la travesía de los barcos europeos sobre el Atlántico, pero el balanceo de las olas alteraba la oscilación del péndulo. En el siglo XVIII estos relojes se dilataban por el calor y su funcionamiento fue lento, en la época de frío se contraían, lo que ocasionó horas incorrectas. Harrison construyó relojes con metales de acero y latón, fue la solución de este problema y en 1759 a su reloj H-3, con ruedas dentadas, le incorporó rubíes y diamantes para un mejor funcionamiento. El H-4 se usó en altamar entre 1760 y 1764 con excelentes resultados, al grado de que la armada real inglesa de su majestad dominó los océanos del mundo gracias al inventó de Harrison. ${ }^{14}$

$\mathrm{Al}$ conocer estos casos Diego de Guadalajara estuvo al tanto del desarrollo técnico de la relojería inglesa; mediante su respectivo periódico novohispano fue un teórico en la construcción de relojes mecánicos y al ser catedrático de matemáticas de la Academia de San Carlos era un profesionista y especialista, no un aficionado en la explicación de la física newtoniana ni tampoco era artesano en el armado de relojes mecánicos. ${ }^{15}$

12 Sobel. Longitud. La verdadera historia de un genio solitario que resolvió el mayor problema científico de su tiempo, p. 57.

13 Azuela, El Matemático, pp. 130, 134 y 173-178.

14 Sobel, op. cit., pp. 33-36, 63 y 92-113.

15 Cipolla, Las máquinas del tiempo, pp. 35-42. 
En lo referente a la matemática, De Guadalajara señaló que ésta es importante en la pintura, por sus principios de la perspectiva, en la escultura porque se utiliza la geometría de los sólidos, y también se emplea en la dinámica, óptica, estática e hidráulica. ${ }^{16}$

Explicó en su curso de matemáticas de la Real Academia de San Carlos (1790), aritmética, álgebra, ecuaciones de segundo grado, geometría elemental, trigonometría, geometría práctica y secciones cónicas aplicadas en la dinámica y perspectiva; $;^{17}$ utilizando a los "autores modernos". El método a seguir fue demostrar las proposiciones o teoremas con el modelo inductivo-deductivo, conocido también como síntesis y análisis, el cual fue empleado por Newton y el novohispano Ignacio Bartolache. Uno de los libros utilizados por De Guadalajara en su curso fue Principios de Matemáticas, de Benito Bails, editado en tres tomos, donde se detalla el cálculo y la matemática más avanzada de la época. ${ }^{18}$

El manuscrito de De Guadalajara dedicado a la matemática está perdido, por lo anterior haremos alusión a que participó activamente como un hombre relacionado con la ciencia de los números al trabajar en proyectos de ingeniería e hidráulica de la corona española, su capacidad matemática no solamente quedó constatada como teórico de la ciencia de los relojes, reparador de los mecánicos de bolsillo y de relojes mecánicos públicos, sino también como académico de la cátedra de matemáticas de San Carlos, además de haber usado la matemática en la ingeniería hidráulica.

Sobre este científico sólo conservamos sus análisis geométricos en el desagüe de Huehuetoca y algunos planos de 1796: uno de corte vertical de la laguna de Zumpango, tres planos delineados, para la longitud del terreno nivelado, un plano iconográfico del canal de Huehuetoca y otro plano iconográfico del canal de Nuestra Señora de Guadalupe.

En la construcción del desagüe de Huehuetoca también participó con Antonio González Velázquez, quien combinó su profesión de arquitecto y profesor, participó en dos construcciones de gran magnitud del Estado

16 Archivo de la Antigua Academia de San Carlos, (en adelante AAASC), doc. 592, ff. 1v.-2v. 17 AAASC, doc. 592 , f. $3 \mathrm{v}$.

18 Ibid., doc. 727, f. 1r. Acerca del desarrollo de la matemática newtoniana en la Academia de San Carlos se puede consultar a Juan Manuel Espinosa Sánchez, "La Matemática Newtoniana en la Real Academia de San Carlos de la Nueva España, a finales del siglo de la Ilustración y Principios del siglo XIX", 4 pp. 
virreinal: el desagüe de Huehuetoca y el camino México-Toluca, en el primer proyecto, González, De Guadalajara y Tres Palacios revisaron el real desagüe entre 1798 y $1802 .{ }^{19}$ En su informe elaborado en 1798, sobre el reconocimiento hecho del nuevo canal del desagüe real llamado San Cristóbal, mencionó que los trabajos de nivelación se habían llevado a cabo en una distancia de 100 varas y que en los lugares donde estaban los socavones hubo derrumbes los cuales representaban un peligro para contener el curso del agua. ${ }^{20}$

Acerca del tajo de Zumpango, González, en su informe de 1801, explicó que el terreno de la obra era defectuoso y aconsejó perfeccionar el tajo cortando las paredes o lados del mismo en líneas de descenso con un ángulo de 45 grados, retirar las tierras de los bordes y abrir una zanja. ${ }^{21}$

Cosme de Mier y Tres Palacios decidió abrir dos tajos entre los años 1796 y 1798, uno en la laguna de Zumpango y el otro en la de San Cristóbal, para desaguar el canal de Huehuetoca. Tenían una longitud de 9,000 y 13,000 metros respectivamente, su idea era unirlos a unos 5,000 metros para incorporarse con la corriente de Cuautitlán, la obra estuvo a cargo de Diego de Guadalajara. ${ }^{22}$

El resultado de este laborioso esfuerzo fue incompleto, dado el peligro que provocó el desbordamiento del lago de Texcoco en la temporada de lluvias; la posibilidad de una inundación en la ciudad de México fue latente para el Estado virreinal, ${ }^{23}$ así como los daños consecuentes y los ocurridos por esa situación en años anteriores: infecciones y mortandad entre los habitantes.

Antonio González elaboró en 1788 dos manuscritos, uno de geometría y el otro de arquitectura; para sus alumnos de la Academia de San Carlos y junto con De Guadalajara y Tello fueron los matemáticos de la Ilustración novohispana que colaboraron al servicio del Virreinato. ${ }^{24}$ De Guadalajara

19 Archivo Histórico del Ayuntamiento de México, (en adelante AHAM), Desagüe, leg. 1, exp. 28 , ff. 14r-14v. En 1604 se inició la obra del desagüe de Huehuetoca por orden del virrey Juan de Mendoza y Luna, marqués de Montesclaros, debido a la inundación que sufrió la capital de la Nueva España en el mes de agosto del citado año. Véase José Sala Catalá, Ciencia y Técnica en la Metropolización de América, pp. 99-119.

20 анам, Desagüe, leg. 1, exp. 37, f. 1v.

21 Ibid., ff. $2 \mathrm{r}-2 \mathrm{v}$.

22 Gurría Lacroix, El Desagüe del Valle de México Durante la Época Novohispana, pp. 150-152.

23 Lemoine Villacaña, El Desagüe del V alle de México Durante la Época Independiente, p. 14.

24 Cordero Herrera, "La Academia de San Carlos dentro del Movimiento de la Ilustración en México", p. 52. 
usó sus conocimientos teóricos sobre matemáticas y física newtoniana en la elaboración de relojes.

\section{La mecánica newtoniana en la construcción de relojes mecánicos en la Nueva España ${ }^{25}$}

En la Nueva España del siglo XVIII hubo varios relojeros además de Diego de Guadalajara como José Rebollo Lozano, Juan Calderón, ${ }^{26}$ Pablo Gay, ${ }^{27}$ José Camacho de Mendoza, ${ }^{28}$ Marcos Rafael del Muro, ${ }^{29}$ Antonio de Alzate, ${ }^{30}$ José Francisco Dimas Rangel ${ }^{31}$ y Manuel Tolsá.

Diego de Guadalajara y Tello fue el relojero "oficial" del virreinato en la Nueva España, por orden del virrey Revillagigedo en $1790 .{ }^{32}$ Su trabajo consistía en revisar el mantenimiento de los dos relojes mecánicos de la ciudad de México, uno ubicado en la catedral metropolitana y el otro en el real palacio, tenía el deber de atender su buen funcionamiento, arreglarlo a la hora correcta del día y ocuparse de las reparaciones. ${ }^{33}$

25 Acerca del desarrollo de la física newtoniana y su aplicación en la Nueva España se puede consultar a Juan Manuel Espinosa Sánchez, "Newton en la Ciencia Novohispana del siglo xviII", pp. 156-219 y del mismo autor el artículo, "Ciencia y técnica en el último tercio del siglo XVIII en México: la construcción hidráulica en el río Xamapa de Medellín, Veracruz", núm. 4, pp. 35-41.

26 Rebollo Lozano y Calderón trabajaron con Diego de Guadalajara en la reparación y ajuste de los relojes mecánicos de la catedral metropolitana y del palacio virreinal. AGN, Obras Públicas, vol.31, ff. 84r-94r.

27 Gay fue sucesor de Lozano como relojero del palacio virreinal en 1794. AGN, Obras Públicas, vol.10, exp. 10, ff. 218r-224r.

28 José Camacho de Mendoza ajustó un reloj mecánico traído de Inglaterra, por encargo del gobernador de Veracruz, en 1774. Agn, Obras Públicas, vol. 22, exp. 13, ff. 307r-319r. Los relojes mecánicos ingleses también fueron exportados a Europa Continental, islas Barbados y Nueva Inglaterra. En Cipolla, op. cit., p. 65.

29 Del Muro construyó en De Guadalajara en 1785, un reloj mecánico siguiendo al inglés Elicot. Gazeta de México, núm.41, martes 5 de julio de 1785, México, Imp. De Francisco de Zúñiga y Ontiveros, martes 5 de julio de 1785, p. 329.

30 Antonio Alzate escribió "El método para probar la bondad de los relojes de bolsa", en su Diario Literario de México, núm.7, el 4 de mayo de 1768, en donde citó a Sully y su obra Régle artificille du temps y a Saverien con su obra Diccionario Matemático y Físico. José de Alzate, Obra, I. Periódicos, pp. 49-50.

31 Rangel construyó once relojes grandes mecánicos para iglesias y civiles. Eduardo Piña Garza, Los Relojes de México, pp. 110-113.

32 AgN, Obras Públicas, vol. 31, f. 90r.

33 Ibid., ff. 84r.-85r. y 87r.-94r. 
Además de ser un buen relojero de su época ${ }^{34}$ editó el periódico Advertencias y Reflexiones más conducentes al buen usó de los relojes y otros Instrumentos Matemáticos, Físicos y Mecánicos en 1777. En su "Introducción y Plan de la Obra”, De Guadalajara se declaró ser seguidor de la mecánica newtoniana, al indicar que ésta sirve para aplicar correctamente la potencia motriz en los relojes. ${ }^{35}$

Cabe recordar que en los relojes de los siglos XVI, XVII y hasta mediados del siglo XVIII, las piezas internas se hacían de madera; eran imprecisos en dar el tiempo; empleaban el modelo geométrico y aritmético euclideano, con una física aristotélica, cartesiana -aunque tiene adelantos como la geometría analítica- con esta influencia están Copérnico en el siglo XVI, Kepler, Galileo, Huygens en el siglo XVII, quienes rechazaron el aristotelismo, pero seguían utilizando la matemática euclidiana en sus trabajos y Huygens en la filosofía cartesiana. ${ }^{36}$

Los Principia de Newton abrieron el camino al analizar la filosofía natural en la precisión matemática, con el cálculo de fluxiones, en óptica, mecánica,

34 Dimas Rangel y De Guadalajara fueron los mejores relojeros novohispanos a finales del siglo XVIII. De Rangel se desconoce su fecha de nacimiento, pero las fuentes mencionan que nació en Valladolid en la Nueva España, además participó en las tertulias organizadas por el virrey Flores al lado de Antonio Alzate y Antonio de León y Gama. A fines del siglo XvIII Rangel construyó un reloj mecánico para la iglesia metropolitana; también fabricó relojes mecánicos que fueron enviados al virreinato del Perú. En 1787 escribió las Advertencias para el buen uso de los relojes de faltriquera y para hacer juicio de su bondad, el documento está extraviado. En 1789 elaboró el Discurso físico sobre la formación de las auroras boreales. Además en 1791 redactó la "Carta de D. Francisco Rangel al Autor de la Gazeta de Literatura que contiene varias reflexiones tocantes al sistema de D. Antonio de León y Gama, al pie de ellas ciertas Notas de un Anónimo", publicado en la Gaceta de Literatura. Rangel también fue impresor y grabador, falleció aproximadamente en 1814. Se pueden consultar las siguientes obras; José Mariano Beristain y Souza, Biblioteca Hispano Americana Septentrional, vol. I, p.9; Andrés Cavo, Suplemento a la Historia de los tres siglos de México durante el gobierno español, vol. III, p. 89; Gazeta de México, núm. 38, p. 312; Gazeta de México, núm.40, p. 328. Sobre la labor científica de Rangel se pueden consultar los siguientes trabajos: Juan Manuel Espinosa Sánchez y Patricia Aceves, "Un científico Newtoniano en la Nueva España del último tercio del Siglo XVIII: Antonio de León y Gama”, pp. 17-25 y Heréndira Téllez Nieto y Juan Manuel Espinosa Sánchez, "La astronomía teórica novohispana: Francisco Dimas Rangel y la aurora boreal de 1789”, pp. 183-210.

35 De Guadalajara y Tello, Advertencias y Reflexiones conducentes al buen uso de los Relojes, "Introducción y Plan de la Obra", p. 2. El periódico de De Guadalajara era para especialistas en la técnica relojera; no iba dirigido al pueblo, sino a los lectores con una cultura científica y técnica, como puede verse por su vocabulario y erudición empleados en el conocimiento de los relojeros ingleses y sus respectivos inventos. Véase María Dolores Sáiz, Historia del Periodismo en España, vol. 1, pp. 87-93 y 174.

36 Azuela, La Ciencia Renacentista, pp. 9-109. 
astronomía, física; en la construcción de mejores instrumentos científicos; ${ }^{37}$ en el estudio de los metales, y con ello en la perfección de los mecanismos de relojería, para el desarrollo de la navegación oceánica y la comprensión del cosmos. ${ }^{38}$

La matemática newtoniana se aplica en la mecánica y también en la construcción de un nuevo lenguaje para el estudio de: espacio, tiempo, velocidad, aceleración, fuerza, entre otros conceptos que fueron interpretados con una nueva matemática; con nuevas concepciones en la explicación de la naturaleza y un novedoso método científico, en la investigación del cosmos con un proceso de mecánica para la solución de diversos problemas, ${ }^{39}$ entre ellos la fuerza motriz, mediante un análisis científico que prescindía de Dios en la explicación newtoniana de movimiento. ${ }^{40}$

¿Qué era la fuerza motriz para Newton? En sus Principia, en la Definición VIII mencionó: "La cantidad motriz de una fuerza centrípeta es una medida proporcional al movimiento que genera en un tiempo dado". Newton explica el término de fuerza motriz al afirmar:

[...] quiero decir que refiero la fuerza motriz al cuerpo como un esfuerzo y propensión del conjunto hacia un centro surgido de las propensiones de las diversas partes en su conjunto [...] Por lo cual la fuerza acelerativa será a la motriz lo que la celeridad es al movimiento. Porque la cantidad de movimiento surge de la celeridad multiplicada por la cantidad de materia, y la fuerza motriz surge de la acelerativa multiplicada por la misma cantidad de materia, pues la suma de las acciones de la fuerza acelerativa sobre las diversas partículas del cuerpo es la fuerza motriz del todo. ${ }^{41}$

37 La diferencia entre el modelo cartesiano y la ciencia newtoniana es un tema amplio que no tocaremos aquí debido a que es pauta para otra investigación; la bibliografía es amplia al respecto, se puede consultar un par de obras básicas sobre el tema Alexander Koyré, Newtonian Studies, pp. 95-96, e I. Bernard Cohen, La Revolución newtoniana, p. 124. 38 Ibid., pp. 26 y 98.

39 Azuela, El Matemático, p. 107.

40 Hawking, S., Dios creó los números. Los descubrimientos matemáticos que cambiaron la historia, pp. 340-344.

41 Newton, Principios matemáticos de la filosofía natural, pp. 227 y 228. 
Posteriormente Newton retomó esta definición para proponer su segunda ley de movimiento, la cual se refiere al siguiente postulado: "el cambio de movimiento es proporcional a la fuerza motriz impresa y se hace en la dirección de la línea recta en la que se imprime esa fuerza." Con esta ley afirmó que el efecto de una fuerza externa sobre un cuerpo produce un cambio en su estado de reposo, ${ }^{42}$ explicando que una "fuerza cualquiera genera un movimiento".

En la tercera ley de movimiento Newton mencionó que: "para toda acción hay siempre una reacción opuesta e igual. Las acciones recíprocas de dos cuerpos entre sí son siempre iguales y dirigidas hacia partes contrarias." Aquí, Newton explicó que los movimientos de los cuerpos son producidos por fuerzas y los cuerpos tienen direcciones opuestas. ${ }^{43}$ La fuerza es la acción externa a los cuerpos en movimiento y debe haber una igualdad entre la acción y la reacción. ${ }^{44}$

Con la dinámica newtoniana se explicaron los movimientos de los cuerpos en la Tierra y en el macrocosmos, además, en el escolio de los Principia dedicado a las leyes del movimiento, Newton puso un ejemplo acerca de cómo pueden ser utilizadas la segunda y tercera leyes del movimiento cuando dice:

En relojes e instrumentos similares, construidos a partir de una combinación de ruedas, las fuerzas contrarias que promueven e impiden el movimiento de las ruedas se sostendrán mutuamente unas a otras, si son inversamente proporcionales como las velocidades de las partes de la rueda sobre la cual están impresas. ${ }^{45}$

Con este ejemplo Newton pretendió mostrar cómo pueden ser aplicadas sus leyes de movimiento en la construcción de relojes mecánicos.

42 A. Sellés y Solís, La revolución científica, p. 135.

43 Ibid., p. 238.

44 Ibid., p. 135.

45 Newton, Principios, p. 252. 
¿Cómo aplicó De Guadalajara y Tello la fuerza motriz en los relojes mecánicos? Usó la fuerza motriz, para dar movimiento a la maquinaria del reloj mecánico y también mencionó que la construcción de un reloj “debe ser hecha por un excelente matemático". ${ }^{46}$ Posteriormente, explicó el movimiento de la maquinaria de un reloj. Los primeros relojes construidos con la técnica consistente en el movimiento de las ruedas que hacen mover a otras ruedas y proporcionan una potencia motriz, fueron hechos en Inglaterra. ${ }^{47}$

Además De Guadalajara mencionó que para la fabricación de relojes grandes, el relojero debe tener conocimientos teóricos en su construcción. Estos relojes se usan en las iglesias y en los palacios. ${ }^{48}$ Las ruedas de este tipo de relojes grandes son de acero para mover las manecillas, las cuales son pesadas y metálicas.

¿Qué importancia tiene la construcción de mejores relojes, para la ciencia? De Guadalajara mencionó a relojeros ingleses como Fatio, Quare, Windimills, Huberte y Grahan, quienes construyeron relojes que fueron usados en varios observatorios astronómicos. Al emplear los relojes ingleses, los astrónomos obtuvieron mejores resultados, midiendo el tiempo de los fenómenos celestes como un eclipse, un cometa y el paso de Venus por el disco solar, entre otros. Estos relojes de ingeniería inglesa tienen segunderos, lo cual permite a los científicos tener medidas temporales más exactas al estudiar el macrocosmos. ${ }^{49}$

¿Cuál es la importancia de construir relojes de gran tamaño? De Guadalajara indicó que los especialistas ingleses armaron este tipo de relojes entre Elicot y San-Levy. Este último trabajó para la reina de Inglaterra. San-Levy empleó el cálculo en la construcción de ruedas y piñones. Para que los engranes de la maquinaria de los relojes grandes tuvieran un buen movimiento, estos instrumentos mecánicos disponían de campanas y música. De Guadalajara llamó a los relojes grandes públicos, porque son "maquinarias para medir el tiempo, advierten las horas y distribuciones

46 De Guadalajara, op., cit., núm. 2, 12 de junio de 1777, p. 7.

47 Ibid., núm. 4, 12 de agosto de 1777, pp. 3-4. En la época de Newton la maquinaria de los relojes era de madera, por lo que hay una innovación técnica con las construcciones relojeras de acero. Vid., Alexandre Koyré, Pensar la Ciencia, p. 88.

48 De Guadalajara, op., cit, núm. 5, 12 de septiembre de 1777, p. 4.

49 Ibid., núm. 3, 12 de junio de 1777, p. 6. 
de los divinos oficios y funciones de nuestra sagrada religión y regulan el trabajo" de la sociedad..$^{50}$

Los relojes grandes y públicos tienen defectos: se atrasan o su maquinaria se para por completo y al ajustarlos, el relojero tiene que emplear el reloj solar en la regulación del tiempo del reloj mecánico. ${ }^{51}$

Es de suma importancia recordar, que en la construcción de relojes solares, se requerían conocimientos de astronomía, aritmética, trigonometría esférica y óptica descriptiva. El reloj solar funciona mediante el movimiento del Sol, cuya luminosidad se refleja en el gnomon, que a su vez proyecta una sombra en la carátula del reloj, para indicar la hora. Estos relojes no se atrasan y sólo dejan de funcionar por un eclipse solar o un día nublado, por ello trasciende la importancia de los relojes solares. ${ }^{52}$

En la fabricación de los relojes mecánicos se utiliza la mecánica de Newton, es decir, la segunda y tercera ley de movimiento, ambas se aplican para proporcionar la fuerza motriz a la maquinaria del reloj. En el siglo XVIII en Europa y América se siguieron armando relojes mecánicos con los postulados de Newton, ${ }^{53}$ pero también se construyeron relojes solares, por ejemplo: Manuel Tolsá construyó uno en el obelisco del Monte de la Cruces, en el camino México-Toluca en abril de $1795 .^{54}$

En la ciencia y la técnica de la construcción de relojes mecánicos hay un progreso. La exactitud de los relojes ingleses condujo a su utilización en las observaciones astronómicas y permitió a los astrónomos tener medidas más precisas de los fenómenos celestes. La Nueva España siguió esta dirección. ${ }^{55}$

50 Ibid., núm. 1, 12 de mayo de 1777, p. 6.

51 Ibid., "Introducción y Plan de la Obra", p. 3. 52 Un estudio sobre los relojes solares en la Nueva España es el de, Juan Manuel Espinosa Sánchez, "Los relojes solares de la Real y Pontificia Universidad de México del siglo XVII", pp. 35-47.

53 Sobre la difusión de las obras matemáticas de Isaac Newton en la Nueva España del siglo XVIII, se puede consultar a Juan Manuel Espinosa Sánchez,'La obra científica y matemática de Newton en la biblioteca de Antonio de León y Gama, en la época de la Ilustración novohispana", pp. 35-50.

54 Agn, Caminos y Calzadas, vol. 19, exp. 13, f. 350r. El camino carretero México-Toluca se construyó por el proceso económico de la región occidente de la Nueva España para abastecer de semillas, ganado, leña y otros productos alimenticios a la ciudad de México, en donde se observa que el mejoramiento económico va acompañado del progreso de la tecnología. Véase a John Tutino, "Las Nuevas Españas. Los Orígenes del Capitalismo, ¿Y qué pasó?", pp. 69-70.

55 En la Nueva España se utilizaron instrumentos más precisos en la astronomía, con Antonio de León y Gama y Joaquín Velázquez de León al observar y estudiar el eclipse total de sol de 1778. 
Los ingleses construyeron relojes aplicando la mecánica de Newton, para dar movimiento a la maquinaria y los perfeccionaron al hacerles incrustaciones de rubíes y diamantes en las piezas de acero y latón; además agregaron manecillas para marcar los segundos y tener una precisión exacta en la medición del tiempo.

Diego de Guadalajara conoció los trabajos de los referidos relojeros de Inglaterra y aplicó la física de Newton en la relojería novohispana a finales del siglo XVIII. La aplicación de la física newtoniana en la época de la Ilustración es una muestra de desarrollo y un rasgo de modernidad $^{56}$ en la ciencia de Europa y de América.

\section{Reflexión final}

Al estudiar a un personaje como Diego de Guadalajara, integrante de la comunidad científica-técnica del último tercio del siglo XVIII, ${ }^{57}$ se advierte que los miembros de esta comunidad establecieron el avance de la ciencia y la técnica mediante la aplicación de los postulados newtonianos en su entorno.

Diego de Guadalajara es un ejemplo del estudioso novohispano que contribuyó al desarrollo de la ciencia y la tecnología en América al interesarse en la construcción de relojes mecánicos, así como en la divulgación científica, por medio de un periódico donde analizó la manufactura de tales dispositivos. A través de la interpretación del legado que dejó De Guadalajara es posible tener una perspectiva de la comunidad de relojeros novohispanos y un acercamiento a su entorno histórico-cultural, ${ }^{58}$ a partir de la noción que se tenía de la ciencia en el siglo XVIII, cuando en el otro lado del mundo y también con la participación de la física de Newton se daba el movimiento cultural conocido como la Ilustración.

56 Richta, "The Scientific and Technological Revolution and the Prospects of Social Development", pp. 11-72.

57 Trabulse distingue a la comunidad científica de la época de la Ilustración novohispana y da una serie de nombres para matizar el desarrollo de la ciencia y la técnica logrado por quienes conformaron dicha comunidad. Véase su libro, Arte y Ciencia en la Historia de México, pp. 3549. El término comunidad científica-técnica se aplica cuando un grupo de dicha comunidad "realiza intervenciones sobre el espacio: arquitectos, ingenieros, agrónomos y militares." Véase Horacio Capel, Historia de la Ciencia y las Disciplinas Científicas, p. 23.

58 Quemain, “Escritura y Lectura de la Historia. Entrevista con Roger Chartier”, p. 119. 


\section{Siglas}

AAASC Archivo de la Antigua Academia de San Carlos

AGN Archivo General de la Nación

AHAm Archivo Histórico del Ayuntamiento de México

\section{Bibliografía}

Attali, Jacques, Historias del Tiempo, México, Fondo de Cultura Económica, 1985. Alzate, José de, Obra, I. Periódicos, México, Instituto de Investigaciones Bibliográficas-UnAM, 1980.

Azuela, Arturo, La Ciencia Renacentista, México, Instituto Politécnico Nacional, 1995. , Las Ciencias y el Quijote, Gijón, Ateneo Jovellanos, 2005. , El Matemático, México, Instituto Politécnico Nacional, 1999.

Beristain y Souza, José Mariano, Biblioteca Hispano Americana Septentrional, vol. I, México, Imp. de Alejandro Valdés, 1816.

Capel, Horacio, Historia de la Ciencia y las Disciplinas Cientificas, México, Facultad de Filosofía y Letras-unAm, 1990.

Cavo, Andrés, Suplemento a la Historia de los tres siglos de México durante el gobierno español, vol. III, México, Imp. de Alejandro Valdés, 1836.

Cházaro, Laura, "Los instrumentos científicos de la Nueva España: circulación, usos y transformaciones de la medición", en Gaceta de la Real Sociedad Matemática Española, vol. 4, núm. 2, 2011, pp. 739-752.

Cipolla, Carlo M., Las máquinas del tiempo. Estudios sobre la Génesis del Capitalismo, Barcelona, Crítica, 2010.

Cohen, Bernard I., La Revolución Newtoniana y la Transformación de las Ideas Cientificas, Madrid, Alianza, 1983.

Cordero Herrera, Alicia Leonor, "La Academia de San Carlos dentro del Movimiento de la Ilustración en México", México, tesis para obtener el grado de maestro en artes plásticas, Universidad Iberoamericana, 1967. Espinosa Sánchez, Juan Manuel, "Ciencia y técnica en el último tercio del siglo XVIII en México: la construcción hidráulica en el río Xamapa de Medellín, Veracruz", en Coincidencias, núm. 4, México, Universidad de Quintana Roo/Plaza y Valdés, julio-diciembre, 2006, pp. 35-41. 
, "La matemática newtoniana en la Real Academia de San Carlos de la Nueva España, a finales del siglo de la Ilustración y principios del siglo XIX", en Memorias del Primer Congreso Internacional Sobre la Enseñanza de las Matemáticas, Estado de México, FES-Cuautitlán, UnAM, mayo 2009, 4 pp.

, "Newton en la ciencia novohispana del siglo XVIII", tesis doctoral en humanidades, área de historia, México, UAM-I, 2006.

, "La obra científica y matemática de Newton en la biblioteca de Antonio de León y Gama, en la época de la Ilustración novohispana”, en Mathesis, Filosofía e Historia de la Ideas Matemáticas, serie III, vol. IV, núm.1, México, Facultad de Ciencias-unam, Enero-Junio, 2009, pp. 35-50.

"La óptica novohispana en la segunda mitad del siglo XVIII", tesis de licenciatura en historia, México, Facultad de Filosofía y Letras de la UNAM, 1994.

"Los relojes solares de la Real y Pontificia Universidad de México del siglo xvII" en la Revista América a Debate, núm.12, Facultad de Historia de la Universidad Michoacana de San Nicolás de Hidalgo, juliodiciembre, 2007, pp. 35-47.

Espinosa Sánchez, Juan Manuel y Patricia Aceves, "Un científico newtoniano en la Nueva España del último tercio del siglo XVIII: Antonio de León y Gama”, en Celina Lertora Mendoza (comp.), Newton en América, BuenosAires, Argentina, Fepai, 1995, pp.17-25.

Gaz̧eta de México, núm. 38, México, Imp. de Felipe de Zúñiga y Ontiveros, martes 24 de mayo de 1785, p. 312.

núm. 40, México, Imp. de Felipe de Zúñiga y Ontiveros, martes 21 de junio de 1785, p. 328.

González Claverán, Virginia, La Expedición Científica de Malaspina en la Nueva España (1789-1794), México, El Colegio de México, 1988.

Guadalajara y Tello, Diego, de, Advertencias y reflexiones conducentes al buen usó de los Reloxes y otros Instrumentos Matemáticos, Físicos y Mecánicos, Imp., de Felipe de Zúñiga y Ontiveros, 1777.

Gurría Lacroix, Jorge, El desagüe del V alle de México durante la época novohispana, México, Instituto de Investigaciones Históricas-unam, 1978.

Hawking, S. Dios cré los números. Los descubrimientos matemáticos que cambiaron la historia, Barcelona, Crítica, 2010. 
Koyré, Alexandre, Newtonian Studies, Cambridge, Harvard University, 1965. Pensar la Ciencia, España, Paidós, 1994.

Lemoine Villacaña, Ernesto, El Desagüe del Valle de México Durante la Época Independiente, México, Instituto de .Investigaciones Históricas-unAm, 1978. Newton, Isaac, Principios Matemáticos de la Filosofía Natural, Madrid, Editora Nacional, 1982.

Paz Ramos, Lara María de la, Difusión e Institucionalización de la mecánica newtoniana en México en el siglo XVIII, México, Sociedad Mexicana de Historia de la Ciencia y la Tecnología-Universidad Autónoma de Puebla, 1994.

Piña Garza, Eduardo, Los relojes de México, México, UAm-Azcapotzalco, 1994. Quemain, Miguel Ángel, "Escritura y Lectura de la Historia. Entrevista con Roger Chartier", Legajos. Boletín del Archivo General de la Nación, séptima época, núm. 2, pp. 117-134.

Richta, Radovan, "The Scientific and Technological Revolution and the Prospects of Social Development", en World Congress of Sociology $8^{\text {th }}$, Scientific-Technological Revolution: Social Aspects, Toronto, Sage, 1974, pp. $11-72$.

Sáiz, María Dolores, Historia del Periodismo en España, v.1, España, Alianza, 1983.

Sala Catalá, José, Ciencia y Técnica en la Metropolización de América, Madrid, Doce Calles-Consejo Superior de Investigaciones Científicas, 1994.

Sellés, Manuel A. y Carlos Solís, La Revolución Científica, España, Síntesis, 1994.

Sobel, Dava, Longitud. La verdadera historia de un genio solitario que resolvió el mayor problema cientifico de su tiempo, Madrid, Debate, 1998.

Téllez Nieto, Heréndira y Juan Manuel Espinosa Sánchez, "La astronomía teórica novohispana: Francisco Dimas Rangel y la aurora boreal de 1789”, en Relaciones, vol. xxx, núm. 117, del Colegio de Michoacán, Invierno del 2009, pp. 183-210.

Trabulse, Elías, Arte y Ciencia en la Historia de México, México, Fomento Cultural Banamex, 1995.

Tutino, John, "Las Nuevas Españas. Los orígenes del capitalismo, ¿y qué pasó?, en Legajos, Boletín del Archivo General de la Nación, núm. 4, México, Secretaría de Gobernación, abril-junio, 2010, pp. 63-74. D 